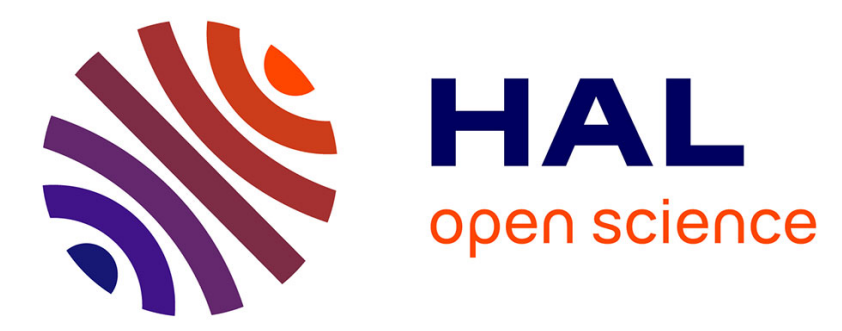

\title{
Hardness of materials at high temperature and high pressure
}

\author{
Vladimir A. Mukhanov, Oleksandr O. Kurakevych, Vladimir L. Solozhenko
}

\section{To cite this version:}

Vladimir A. Mukhanov, Oleksandr O. Kurakevych, Vladimir L. Solozhenko. Hardness of materials at high temperature and high pressure. Philosophical Magazine, 2010, 89 (25), pp.2117-2127. 10.1080/14786430903032563 . hal-00564476

\section{HAL Id: hal-00564476 https://hal.science/hal-00564476}

Submitted on 9 Feb 2011

HAL is a multi-disciplinary open access archive for the deposit and dissemination of scientific research documents, whether they are published or not. The documents may come from teaching and research institutions in France or abroad, or from public or private research centers.
L'archive ouverte pluridisciplinaire HAL, est destinée au dépôt et à la diffusion de documents scientifiques de niveau recherche, publiés ou non, émanant des établissements d'enseignement et de recherche français ou étrangers, des laboratoires publics ou privés. 


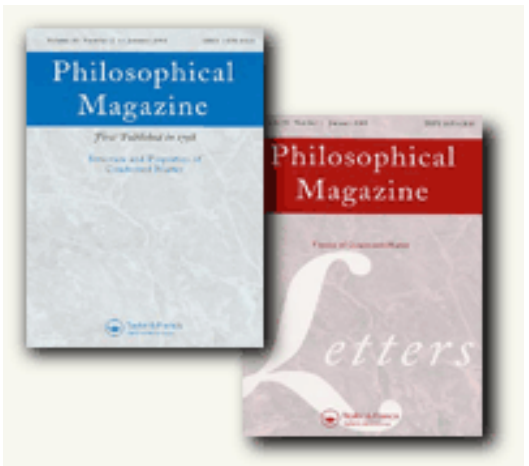

\section{Hardness of materials at high temperature and high pressure}

\begin{tabular}{|c|c|}
\hline Journal: & Philosophical Magazine \& Philosophical Magazine Letters \\
\hline Manuscript ID: & TPHM-09-Feb-0078 \\
\hline Journal Selection: & Philosophical Magazine \\
\hline $\begin{array}{r}\text { Date Submitted by the } \\
\text { Author: }\end{array}$ & 24-Feb-2009 \\
\hline Complete List of Authors: & $\begin{array}{l}\text { Mukhanov, Vladimir; LPMTM-CNRS } \\
\text { Kurakevych, Oleksandr; LPMTM-CNRS } \\
\text { Solozhenko, Vladimir; LPMTM-CNRS }\end{array}$ \\
\hline Keywords: & hardness, inorganic materials \\
\hline Keywords (user supplied): & superhard materials, high temperature, high pressure \\
\hline
\end{tabular}

\section{S) ScholaroNE \\ Manuscript Central}




\title{
Hardness of materials at high temperature and high pressure
}

\author{
V.A. MUKHANOV, O.O. KURAKEVYCH and V.L. SOLOZHENKO* \\ LPMTM-CNRS, Université Paris Nord, Villetaneuse, France
}

\footnotetext{
${ }^{*}$ Corresponding author. Email : vls@1pmtm.univ-paris13.fr
} 
Intrinsic character of correlation between hardness and thermodynamic properties of solids has been established. The proposed thermodynamic model of hardness allows one to easily estimate hardness and bulk moduli of known or even hypothetical solids from the data on Gibbs energy of atomization of the elements or on the enthalpy at the melting point. The correctness of this approach has been illustrated by an example of the recently synthesized superhard diamond-like $\mathrm{BC}_{5}$ and orthorhombic modification of boron, $\gamma-\mathrm{B}_{28}$. The pressure and/or temperature dependences of hardness have been calculated for a number of hard and superhard phases, i.e. diamond, $\mathrm{cBN}, \mathrm{B}_{6} \mathrm{O}, \mathrm{B}_{4} \mathrm{C}, \mathrm{SiC}$, $\mathrm{Al}_{2} \mathrm{O}_{3}, \beta-\mathrm{B}_{2} \mathrm{O}_{3}$ and $\beta$-rh boron. The excellent agreement between experimental and calculated values has been observed for temperature dependences of Vickers and Knoop hardness. Besides, the model predicts that some materials can become harder than diamond already at pressures in the megabar range.

Keywords: superhard materials, theory of hardness, high pressure, high temperature.

\section{Introduction.}

Hardness describes the abrasive properties of materials and is understood as the ability of a material to resist an elastic and plastic deformation or brittle failure [1-3]. Interest in the study of hardness in a wide temperature range covers many fields [4]; i.e. modeling the mechanical behavior of materials in technological processes, assessing the performance of hard tools under extreme conditions, studying the elementary steps of the plastic deformation and fracture of hard materials, etc.

The theories of hardness and design of novel superhard materials are great challenge to materials scientists till now. Many attempts to predict hardness have been made using the structural data and such characteristics as bulk $(B)$ and shear $(G)$ moduli, specific bond energy, band gap $\left(E_{g}\right)$, density of valent electrons (i.e. the number of valent electrons per unit volume $N_{e}$ ), etc. [1-3,5-10]. Up to date the best correspondence between the calculated and experimental values of hardness has been achieved in the recent papers [5,6]. In both cases, the final accuracy is about $10 \%$ for hard phases, i.e. at the level of experimental errors. However, the temperature and pressure dependencies of hardness can be hardly derived from any known model.

The universal model of hardness should also take into account the microstructure of materials (grain size, inter-grain boundaries, etc.) [3,11,12]. However, these factors are usually ignored in theoretical simulations, so that the calculated values correspond to socalled "chemical" hardness that is usually observed only for single crystals and well-sintered polycrystalline bulks. Here we will deal with the "chemical" hardness only.

The purpose of present work was to establish an intrinsic relationship between hardness and thermodynamic parameters of solids; that would allows one to calculate the hardness of materials under extreme pressure-temperature conditions.

\section{Hardness as a function of Gibbs energy of atomization.}


According to our concept, the hardness of a phase is proportional to the atomization energy, which may be considered as a characteristic of the bond rigidity (for clarity, we will use the standard values of Gibbs energy of atomization $\Delta G^{\circ}$ at), and is in inverse proportion to the molar volume of a phase [13] and to the maximal coordination number of the atoms. The value defined in such way has the dimensions of pressure. The plasticity of materials is taken into account by the empirical coefficient $\alpha$. In general case the polarity of bonds leads to the hardness decrease, which may be clearly seen in the sequence of isoelectronic analogues of diamond, i.e. diamond (115 GPa) $[14,15]$ - cubic boron nitride cBN (62 GPa) [16] - BeO (13 ГПа) [3,5,7] - LiF (1.5 ГПа) [3,5,7]. This factor has been evaluated by empirical coefficient $\beta$, which is the measure of the bond covalency.

The formula that allows calculating the Vickers hardness $\left(H_{V}\right)$ of crystals at $298 \mathrm{~K}$ is

$$
H_{V}=\frac{2 \Delta G^{\circ}{ }_{a t}}{V N} \alpha \beta \varepsilon,
$$

where $V$ - molar (atomic) volume $\left(\mathrm{cm}^{3} \operatorname{mole}^{-1}\right) ; N$ - maximal coordination number; $\alpha-$ coefficient of relative (as compared to diamond) plasticity; $\beta$ - coefficient corresponding to the bond polarity (see below); $\varepsilon$ - ratio between the mean number of valent electrons per atom and the number of bonds with neighboring atoms $(N)$ [17]; $\Delta G^{\circ}{ }_{a t}-$ standard Gibbs energy of atomization $\left(\mathrm{kJ} \mathrm{mole}^{-1}\right)$ of compound $X_{m} Y_{n}$.

$$
\Delta G_{a t X_{m} Y_{n}}^{\circ}=m \Delta G_{a t X}^{\circ}+n \Delta G_{a t Y}^{\circ}-\Delta G_{f X_{m} Y_{n}}^{\circ} ;
$$

where $\Delta G_{f X_{m} Y_{n}}^{\circ}$ - standard Gibbs energy of formation of $X_{\mathrm{m}} Y_{\mathrm{n}}, \Delta G_{a t X}^{\circ}$ and $\Delta G_{a t Y}^{\circ}-$ standard Gibbs energy of atomization of elements $X$ и $Y$.

Coefficient $\alpha$ has been estimated from the experimental values of $H_{V}$ for diamond, $\mathrm{d}-\mathrm{Si}$, d-Ge and d-Sn. For the elementary substances and compounds of second period elements $\alpha$ equals 1 , while for other periods $(\geq 3) \alpha$ makes 0.7 . This coefficient reflects the difference in the bond strength [6] for the elements of different periods.

Coefficient $\beta$ (square of the covalency $f$ ) has been calculated by the equation

$$
\beta=\left(\frac{2 \chi_{Y}}{\chi_{Y}+\chi_{X}}\right)^{2} ;
$$

where $\chi_{\mathrm{X}}, \chi_{\mathrm{Y}}-$ electronegativities of the elements by Pauling, $\chi_{\mathrm{X}}>\chi_{\mathrm{Y}}$ [18]. For elementary substances $\beta=1$.

For the refractory crystalline compounds the values of hardness calculated by equation (1) are in a very good agreement (less than $4 \mathrm{GPa}$ of discrepancy, i.e. $<7 \%$ ) with the experimental values [4-7,14-16,18-31] (Fig. 1a [32]). 
One more advantage of the proposed method is the possibility to estimate the hardness of various forms of boron and its compounds $\left(\mathrm{B}_{4} \mathrm{C}, \mathrm{B}_{6} \mathrm{O}, \mathrm{B}_{13} \mathrm{~N}_{2}\right)$, that is rather complicated by using other methods because of extreme complexity of boron-related structures.

The experimental values of hardness for the $\alpha-\mathrm{B}_{12}\left(H_{V}=42 \mathrm{GPa}\right)$ and $\beta-\mathrm{B}_{106}$ $\left(H_{V}=45 \mathrm{GPa}\right)$ phases [33] are in good agreement with the values $(39.2$ and $43.8 \mathrm{GPa}$, respectively) calculated in the framework of the thermodynamic model of hardness. The hardness of recently synthesized superhard high-pressure boron phase, orthorhombic $\gamma-B_{28}$ [34], was found to be $50 \mathrm{GPa}$ [33], which also well agrees with the calculated value of 48.8 GPa. Our model suggests that $\gamma-\mathrm{B}_{28}$ has the highest hardness among the known crystalline modifications of boron because of its highest density $\left(2.544 \mathrm{~g} / \mathrm{cm}^{3}\right)$.

In our calculations for boron-rich compounds we have taken the mean value of electronegativities of all atoms connected to $\mathrm{B}_{12}$ icosahedron as a $\chi$ value for anion. Thus, the calculated values of Vickers hardness for $\mathrm{B}_{4} \mathrm{C}$ and $\mathrm{B}_{6} \mathrm{O}$ are 44 and $38 \mathrm{GPa}$, respectively; that is in a very good agreement with the experimental data for single crystal $\mathrm{B}_{4} \mathrm{C}\left(H_{V}=45 \mathrm{GPa}\right)$ [19] and polycrystalline $\mathrm{B}_{6} \mathrm{O}\left(H_{V}=38 \mathrm{GPa}\right)$ [21]. The lower value of hardness for $\mathrm{B}_{6} \mathrm{O}$ as compared to $\mathrm{B}_{4} \mathrm{C}$ may be explained by the higher ionicity of the $\mathrm{B}-\mathrm{O}$ bonds than that of $\mathrm{B}-\mathrm{C}$ bonds. The estimation of hardness for the recently synthesized rhombohedral boron subnitride $\mathrm{B}_{13} \mathrm{~N}_{2}$ [35,36] has given $H_{V}=40.3 \mathrm{GPa}$ [37] that allows ascribing $\mathrm{B}_{13} \mathrm{~N}_{2}$ to superhard phases.

Using equation (1) it is possible to calculate the hardness of dense phases with threedimensional structures that have not been synthesized to present time, e.g. $\mathrm{C}_{3} \mathrm{~N}_{4}$ with $\mathrm{Si}_{3} \mathrm{~N}_{4}$ structure [8], $\mathrm{CO}_{2}$ with $\alpha-\mathrm{SiO}_{2}$ structure, hp- $\mathrm{B}_{2} \mathrm{O}_{3}$ with $\mathrm{Al}_{2} \mathrm{O}_{3}$ structure [38] and diamond-like phases of the B-C system $[39,40]$ (see Table 1). The advantage of the proposed method is that only the maximal coordination number is used as a structural data. In all cases the molar volumes have been calculated from the covalent radii of the elements, while $\Delta G_{f}^{\circ}$ values (usually the negligible term as compared with $\Delta G^{\circ}{ }_{a t}$ of the elements) of the phases have been fixed to the standard Gibbs energies of formation of known compounds in the corresponding binary systems, i.e. $\mathrm{C}_{2} \mathrm{~N}_{2}, \mathrm{CO}_{2}, \mathrm{~B}_{4} \mathrm{C}, \beta-\mathrm{B}_{2} \mathrm{O}_{3}[20,22-26,41]$. The applicability of this method for estimating the hardness of hypothetical compounds has been recently illustrated by the example of diamond-like $\mathrm{BC}_{5}\left(\mathrm{c}-\mathrm{BC}_{5}\right)$, a novel superhard phase synthesized under high pressures and temperatures [42]. Vickers hardness of this phase has been calculated to be 70.6 GPa (Table 1), which is in excellent agreement with the experimental value $H_{V}=71 \mathrm{GPa}$ [42].

\section{Hardness as a function of enthalpy at a melting point.}

We have also established that instead of Gibbs energy of atomization, the heat content of a phase at a melting point may be used. The corresponding equation for calculation of Vickers hardness $H_{V}$ is 


$$
H_{V}=\frac{13.2 \int_{298 K}^{T_{m}} C_{p}(T) d T}{\delta N V},
$$

where $C_{p}$ - molar heat capacity $\left(\mathrm{kJ}\right.$ mole $\left.{ }^{-1} \mathrm{~K}^{-1}\right) ; N$ - maximal coordination number; $V$ - molar volume $\left(\mathrm{cm}^{3}\right.$ mole $\left.{ }^{-1}\right) ; \delta$ - empirical coefficient. The main advantage of equation (4) as compared to equation (1) is that in the vicinity of the melting point, the calculated hardness tends to zero; therefore, one can expect that the better correspondence between the experimental temperature dependence of hardness and equation (4). However, equation (4) can be hardly used for prediction of hardness for hypothetical phases.

The experimental hardness of covalent crystals [4-7,14-16,18-31] is in a good agreement with the calculated values (Fig. 2 [43]) (the heat capacity data have been taken from Refs. 24,25 ). For covalent compounds $\delta \approx 1$, while for ionic compounds $\delta>3$. The metals show very good agreement between calculated and experimental values of hardness at $\delta \approx 12$.

\section{Correlation between hardness and bulk modulus.}

In the framework of our approach, the compressibility $K$ of a phase at $298 \mathrm{~K}$ is proportional to the molar volume $V$ and is in inverse proportion to Gibbs energy of atomization $\Delta G^{\circ}{ }_{a t}[44]$, so

$$
K=g \frac{V}{3 f \Delta G_{a t}^{\circ}}
$$

where $f=\sqrt{\beta}=\frac{2 \chi_{Y}}{\chi_{X}+\chi_{Y}}-$ covalency of chemical bonds. The empirical coefficient " 3 " in equation (5) has been evaluated using the experimental data on the compressibility of $\mathrm{cBN}$, $\mathrm{d}-\mathrm{Si}$ and d-Ge [45,46], while $g$ is a correction coefficient usually fixed to 1 (see below). For the majority of the closely packed covalent compounds and metals there is a good agreement between the values of $K_{\text {exp }}$ и $K_{\text {theor }}$, however, for the phases with anisotropic lattices, alkali and some alkali-earth metals the calculated values are lower than the experimental ones. For transition metals of periods V and VI, $g=0.625$ in equation (5). Fig. 1b [47] shows the comparison between experimental and theoretical values of bulk modulus for various compounds $[48,49]$. The remarkable deviation $(g \sim 1.4)$ is observed only for three most hard phases containing carbon, i.e. diamond, cubic $\mathrm{BC}_{2} \mathrm{~N}$ and diamond-like $\mathrm{BC}_{5}$.

By combining equations (1) and (5), obtain 


$$
H_{V}=\frac{2}{3} \frac{g \alpha \varepsilon \sqrt{\beta}}{N} B
$$

that illustrates the famous non-monotone correlation between bulk modulus $B$ (the value inverse to compressibility $K$ ) and hardness $H_{V}$ [50-52].

\section{Hardness at high temperature.}

Equation (1) also allows to calculate the values of hardness at various temperatures by introducing the linear approximation of temperature dependence of $\Delta G_{a t}(T)$, i.e.

$$
\Delta G_{a t}(T)=\Delta G_{a t}(300) \cdot\left[1-(T-300) /\left(T_{a t}-300\right)\right],
$$

where $T_{a t}$ - temperature of atomization [53]; as well as by introducing the temperature dependences of molar volumes $V(T)$. Fig. 3a shows the temperature dependences of Vickers and/or Knoop hardness for diamond, $c B N, \mathrm{ReB}_{2}$ and $\mathrm{Al}_{2} \mathrm{O}_{3}$ in comparison with experimental data $[4,20,54,55]$. The theoretical lines have been calculated by equation

$$
H(T)=H(300) \cdot \frac{\Delta G_{a t}(T) \cdot V(300)}{\Delta G_{a t}(300) \cdot V(T)} .
$$

At relatively high temperatures $\left(\sim 0.3-0.5 T_{a t}\right)$ this equation gives $10-15 \%$ higher values than the observed ones (bold lines on Fig. 3a), that should be attributed to the increase of materials' plasticity due to the intensification of the surface and bulk diffusion [56]. The influence of the temperature on plasticity (coefficient $\alpha$ ) can be taken into account by the following empirical equation:

$$
\alpha(T)=\alpha(300) \cdot\left(1-\frac{k(T)}{k(\infty)}\right)=\alpha(300) \cdot\left(1-e^{-\frac{2 / 3 T_{\text {melt }}}{T}}\right)
$$

that supposes the Arhenius-type temperature dependence of the dislocation propagation constant $k(T)$ (following Ref. 57, the activation energy was set to $2 / 3 R T_{\text {melt }}$ ). This term allows decrease the discrepancy between experimental and calculated data down to the level of experimental error (dashed lines on Fig. 3a).

Equation (4) may be also generalized for calculation of the temperature dependence of hardness $H_{V}(T)$ [or $H_{K}(T)$ ], i.e.

$$
\begin{aligned}
& H_{V}(T)=H_{V}(298) \frac{V_{298}}{H_{m e l t}-H_{298}} \frac{H_{m e l t}-H_{T}}{V_{T}}, \\
& H_{V}(T)=H_{V}(298)-\frac{13.2}{N \delta} \frac{H_{T}-H_{298}}{V_{T}},
\end{aligned}
$$




\section{Hardness at high pressure.}

Previously some suggestions have been made on the increase of hardness with pressure [61]. Because of the lack of reliable data on $\Delta G_{a t}$ and $\Delta H_{m e l t}$ at very high pressures, the prediction cannot be easily made using equations (1) or (4) (the ab initio calculations of corresponding thermodynamic parameters could be useful in this case). However, according to equation (6), pressure dependence of hardness is the same (up to a constant) that pressure dependence of bulk modulus, i.e.

$$
H_{V}(p)=\text { const } \cdot B(p)
$$

or, applying the Murnaghan equation of state [62]

$$
H_{V}(p)=H_{V}(0) \cdot\left(1+\frac{B_{1}}{B_{0}} p\right)=H_{V}(0) \cdot\left(\frac{V(p)}{V_{0}}\right)^{-B_{1}}
$$

Equation (15) allows one to suggest that the hard phases with relatively low bulk moduli should show remarkable hardness increase with pressure. From Fig. 4 it can be clearly seen that some compounds with relatively high hardness at ambient pressure and relatively low bulk modulus become harder more rapidly than diamond under pressure; that allows some of them to reach the diamond hardness (as well as diamond's compressibility) [61] at very high pressures. It is interesting to note that graphite, a very soft material at ambient conditions, may reach diamond hardness at lower pressure than many other materials. This 
fact is in excellent agreement with results reported by Mao et al. [63] on formation of "superhard graphite" that can scratch the single-crystal diamond. One can suggest that other ordered [64-66] and disordered [67-70] graphite-like phases should show similar behavior under high pressure, even if the "compressed state" is not always quenchable down to ambient pressure $[66,67,70]$.

\section{Conclusions.}

Thus, it has been shown that the hardness of solids is directly related to their thermodynamic and structural properties. The formulated equations may be used for a large number of compounds with various types of chemical bonding and structures. The proposed method allows estimating the hardness and compressibility of various hypothetical compounds using the data on the Gibbs energy of atomization of elements and covalent/ionic radii. The capacity of this approach to predict hardness has been illustrated by examples of the recently synthesized superhard diamond-like $\mathrm{BC}_{5}$ [42] and orthorhombic modification of boron, $\gamma-\mathrm{B}_{28}$. In the framework of proposed method we have calculated the temperature dependencies of hardness for diamond, $\mathrm{cBN}, \mathrm{B}_{4} \mathrm{C}, \mathrm{SiC}, \mathrm{ReB}_{2}$ and $\alpha-\mathrm{Al}_{2} \mathrm{O}_{3}$. Besides, it has been shown that in the megabar pressure range some phases can become harder than diamond at the same pressure.

\section{Acknowledgements.}

The authors are grateful to Agence Nationale de la Recherche for financial support (grant ANR-05-BLAN-0141). 


\section{References.}

1. V. V. Brazhkin, A. G. Lyapin and R. J. Hemley, Philosop. Mag. A 82 (2002) p. 231.

2. V. P. Poliakov, A. V. Nozhkina and N. V.Chirikov, Diamonds and superhard materials, Metallurgiya, Moscow, 1990.

3. A. S. Povarennykh, Hardness of minerals, Press of AN USSR, Kiev, 1963.

4. N. V. Novikov, Y. V. Sirota, V. I. Mal'nev, and I. A. Petrusha, Diamond Relat. Mater. 2 (1993) p. 1253.

5. F. M. Gao, J. L. He, E. D. Wu, S. M. Liu, D. L. Yu, D. C. Li, S. Y. Zhang, and Y. J. Tian, Phys. Rev. Lett. 91 (2003) p. 015502.

6. A. Simunek and J.Vackar, Phys. Rev. Lett. 96 (2006) p. 085501.

7. N. V. Novikov (ed.), Synthesis of superhard materials, in Synthetic superhard materials, Naukova Dumka, Kiev, 1986, vol. 1 of 3.

8. D. M. Teter and R. J. Hemley, Science 271 (1996) p. 53.

9. S.-H. Jhi, S. G. Louie, M. L. Cohen and J. Ihm, Phys. Rev. Lett. 86 (2001) p. 3348.

10. J. J. Gilman, Science 261 (1993) p. 1436.

11. E. O. Hall, Proc. Phys. Soc. London B 64 (1951) p. 747.

12. T. G. Nieh and J. Wadsworth, Scripta Metall. Mater. 25 (1991) p. 955-958.

13. E.g. for carbon phases the linear dependence between the hardness and density has been established in Ref. [M. Weiler, S. Sattel, T. Giessen, et al., Physical Review B 53, 1594 (1996)].

14. N. V. Novikov and S. N. Dub, J. Hard Mater. 2 (1991) p. 3-11.

15. H. Sumiya, N. Toda and S. Satoh, Diamond Relat. Mater. 6 (1997) p. 1841.

16. V. L. Solozhenko, S. N. Dub and N. V.Novikov, Diamond Relat. Mater. 10 (2001) p. 2228.

17. The use of this coefficient allows to establish the hardness of the $\mathrm{A}^{\mathrm{I}} \mathrm{B}^{\mathrm{VII}}(\varepsilon=1 / N)$ and $\mathrm{A}^{\mathrm{II}} \mathrm{B}^{\mathrm{VI}}(\varepsilon=2 / N)$ compounds, i.e. $\mathrm{LiF}, \mathrm{NaCl}, \mathrm{BeO}, \mathrm{ZnS}, \mathrm{MgO}$, etc.

18. J. Emsley, The Elements, Clarendon Press, Oxford, 1991.

19. V. Domnich, Y. Gogotsi and M. Trenary, Mater. Res. Soc. Symp. Proc. 649 (2001) p. Q8.9.1.

20. A. V. Kurdyumov, V. G. Malogolovets, N. V. Novikov, A. N. Pilyankevich and L. A. Shul'man, Polymorph modifications of carbon and boron nitride, Metallurgiya, 
Moscow, 1994.

21. H. F. Rizzo, W. C. Simmons and H. O. Bielstein, J. Electrochem. Soc. 109 (1962) p. 1079.

22. V. A. Rabinovich and Z. Ya. Khavin, Small handbook of chemistry, Khimiya, Leningrad, 1997.

23. A. G. Bulakh, Thermodynamic methods in mineralogy, Nedra, Leningrad, 1974.

24. V.P. Glushko, L.V. Gurvich and G.A. Bergman (eds.), Thermodynamic properties of inorganic materials, Press of AN SSSR, Moscow, 1965-1981, 10 vols.

25. L. V. Gurvich, E. A. Khachkuruzov and V. A. Medvedev, Thermodynamic properties of individual substances, Press of AN SSSR, Moscow, 1962, 2 vols.

26. I. L. Knunyants (ed.), Chemical Encyclopedia, Bol'shaia Rossiyskaia Entsiklopediya, Moscow, 1992, 5 vols.

27. P. F. McMillan, H. Hubert, A. Chizmeshya, W. T. Petuskey, L. A. J. Garvie and B. Devouard, J. Solid State Chem. 147 (1999) p. 281.

28. J. Haines and J. M. Leger, J. Superhard Mater. 20 (1998) p. 3.

29. H. Y. Chung, M. B. Weinberger, J. B. Levine, A. Kavner, J. M. Yang, S. H. Tolbert and R. B. Kaner, Science 316 (2007) p. 436.

30. I. Yonenaga, Physica B 308-310 (2001) p. 1150.

31. V. L. Solozhenko, D. Andrault, G. Fiquet, M. Mezouar and D. C. Rubie, Appl. Phys. Lett. 78 (2001) p. 1385.

32. The considered compounds/phases are diamond, Si, Ge, d-Sn, SiC, cBN, wBN, c$\mathrm{BC}_{2} \mathrm{~N}, \alpha$-rh $\mathrm{B}, \beta$-rh $\mathrm{B}, \mathrm{B}_{4} \mathrm{C}, \mathrm{B}_{6} \mathrm{O}, \mathrm{TiC}, \mathrm{Si}_{3} \mathrm{~N}_{4}, \mathrm{BeO}, \mathrm{TiN}, \mathrm{Al}_{2} \mathrm{O}_{3}$, quartz, coesite, stishovite, WC, $\mathrm{ReB}_{2}, \mathrm{LiF}, \mathrm{Al}_{2} \mathrm{SiO}_{4} \mathrm{~F}_{2}, \mathrm{KAlSi}_{3} \mathrm{O}_{8}, \mathrm{Ca}_{5}\left(\mathrm{PO}_{4}\right)_{3} \mathrm{~F}, \mathrm{CaF}_{2}, \mathrm{CaCO}_{3}, \mathrm{BAs}, \mathrm{BP}$, AlN, AlP, AlAs, AlSb, GaN, GaP, GaAs, GaSb, InN, InP, InAs, InSb, ZnS, ZnSe, $\mathrm{ZnTe}, \mathrm{ZnO}$.

33. V. L. Solozhenko, O. O. Kurakevych and A. R. Oganov, J. Superhard Mater. 30 (2008) p. 428.

34. A. R. Oganov, J. Chen, C. Gatti, Y. Ma, Y. Ma, C. W. Glass, Z. Liu, T. Yu, O. O. Kurakevych and V. L. Solozhenko, Nature 457 (2009) p. 863.

35. O. O. Kurakevych and V. L. Solozhenko, Acta Crystallogr., Sect. C 63 (2007) p. i80.

36. V. L. Solozhenko and O. O. Kurakevych, J. Phys.: Conf. Ser. 121 (2008) p. 062001.

37. The $2 \Delta G^{\circ}$ at $/ N V$ value has been set to a mean ( $\left.\sim 51 \mathrm{GPa}\right)$ of corresponding values for $\mathrm{B}_{6} \mathrm{O}$ and $\mathrm{B}_{4} \mathrm{C} ; \beta=0.79$. 
38. V. A. Mukhanov, O. O. Kurakevich and V. L. Solozhenko, J. Superhard Mater. 30 (2008) p. 71.

39. J. E. Lowther, J. Phys.: Cond. Matter 17 (2005) p. 3221.

40. J. E. Moussa and M. L. Cohen, Phys. Rev. B 77 (2008) p. 064518.

41. V. L. Solozhenko, O. O. Kurakevych, V. Z. Turkevich, and D. V. Turkevich, J. Phys. Chem. B 112 (2008) p. 6683.

42. V. L. Solozhenko, O. O. Kurakevych, D. Andrault, Y. Le Godec and M. Mezouar, Phys. Rev. Lett. 102 (2009) p. 015506.

43. The considered compounds/phases are diamond, Si, Ge, d-Sn, cBN, SiC, B ${ }_{4} \mathrm{C}, \beta-\mathrm{rh} \mathrm{B}$, $\alpha-\mathrm{Al}_{2} \mathrm{O}_{3}$, quartz, $\mathrm{Ga}_{2} \mathrm{O}_{3}, \mathrm{Si}_{3} \mathrm{~N}_{4}, \mathrm{GeO}_{2}, \mathrm{GeO}_{2}, \mathrm{Be}_{3} \mathrm{~N}_{2}, \mathrm{Al}_{4} \mathrm{C}_{3}$, hp- $\mathrm{B}_{2} \mathrm{O}_{3}, \mathrm{BeO}, \mathrm{TiO}_{2}, \mathrm{LiF}$, $\mathrm{NaCl}, \mathrm{MgO}, \mathrm{CaO}, \mathrm{SrO}, \mathrm{BaO}, \mathrm{Cr}_{2} \mathrm{O}_{3}, \mathrm{FeO}, \mathrm{Fe}_{2} \mathrm{O}_{3}, \mathrm{ZnO}, \mathrm{ZnS}, \mathrm{CaF}_{2}, \mathrm{CaCO}_{3}$.

44. S. M. Stishov, Phil. Mag. Lett. 80 (2000) p. 125-128.

45. N.M. Baron, Small handbook of physico-chemical values, Khimiya, Leningrad, 1983.

46. A. P. Babichev, N. A. Babushkina, and A. M. Bratkovskiy, Physical values. Handbook, Energoatomizdat, Moscow, 1991.

47. The considered compounds/phases are diamond, $\mathrm{Si}, \mathrm{Ge}, \mathrm{d}-\mathrm{Sn}(\alpha-\mathrm{Sn}), \beta-\mathrm{Sn}, \mathrm{SiC}, \mathrm{cBN}$, c-BC ${ }_{2} \mathrm{~N}, \mathrm{c}-\mathrm{BC}_{5}, \mathrm{BP}, \mathrm{TiC}, \mathrm{ZrC}, \mathrm{WC}, \mathrm{TiN}, \mathrm{ZrN}, \mathrm{SiO}_{2}$ (stishovite), $\mathrm{BeO}, \alpha-\mathrm{Al}_{2} \mathrm{O}_{3}, \mathrm{Al}$, $\mathrm{Ca}, \mathrm{Sr}, \mathrm{Ba}, \mathrm{Li}, \mathrm{Na}, \mathrm{K}, \mathrm{Rb}, \mathrm{Cs}, \mathrm{Ti}, \mathrm{Zr}, \mathrm{Hf}, \mathrm{Sc}, \mathrm{Y}, \mathrm{Zn}, \mathrm{Cd}, \mathrm{Hg}\left(\sim-40^{\circ} \mathrm{C}\right), \mathrm{Cu}, \mathrm{Ag}, \mathrm{Au}, \mathrm{Cr}$, Mo, W, Ni, Pd, Pt, Co, Rh, Ir, Fe, Ru, Os, V, Nb, Ta, P, As, Sb, Bi, I2, NaCl, LiF.

48. V. L. Solozhenko and O. O. Kurakevych, Solid State Comm. 133 (2005) p. 385.

49. V. L. Solozhenko and O. O. Kurakevych, Solid State Comm. 135 (2005) p. 87.

50. R. J. Goble and S. D. Scott, Canad. Mineralog. 23 (1985) p. 273.

51. J. M. Leger, J. Haines and B. Blanzat, J. Mater. Sci. Lett. 13 (1994) p. 1688.

52. W. Yang, R. G. Parr and L. Uytterhoeven, Phys. Chem. Mineral. 15 (1987) p. 191.

53. For diamond and $\mathrm{cBN}$ the corresponding temperatures of sublimation are $4300 \mathrm{~K}$ and $3300 \mathrm{~K}$, respectively. ${ }^{20}$

54. A. Krell and O. V. Bakun, Acta Metall. 34 (1986) p. 1315.

55. S. Otani, M. M. Korsukova, and T. Aizawa, J. Alloy. Comp. in press, doi: 10.1016/j.jallcom.2008.10.094.

56. D. L. Trim, Design of Industrial Catalysts, in Chemical Engineering Monographs Elsevier, Amsterdam, 1980, vol. 11.

57. V. V. Gusarov, Statics and dynamics of polycrystalline systems based on refrectory 
oxides, St Petersbourg State University, St Petersbourg, 1996.

58. H. L. Yakel, J. Appl. Cryst. 6 (1973) p. 471.

59. J. R. O'Connor and J. Smiltens, A High Temperature Semiconductor, Pergamon Press, Oxford, London, New York, Paris, 1960.

60. I. D. Marinescu, H. K. Tonshoff and I. Inasaki, Handbook of Ceramic Grinding and Polishing, Noyes Publications, Berkshire, 2000.

61. W. J. Nellis, J. Phys.: Conf. Ser. 121 (2008) p. 062005.

62. The results are qualitatively similar for any other equation of state having finite value of $\mathrm{B}_{0}$ ' at high pressure.

63. W. L. Mao, H. K. Mao, P. J. Eng, T. P. Trainor, M. Newville, C. C. Kao, D. L. Heinz, J. F. Shu, Y. Meng and R. J. Hemley, Science 302 (2003) p. 425.

64. Y. Meng, H.-k. Mao, P. J. Eng, T. P. Trainor, M. Newville, M. Y. Hu, C. Kao, J. Shu, D. Hausermann and R. J. Hemley, Nature Mater. 3 (2004) p. 111.

65. M. Ueno, K. Hasegawa, R. Oshima, A. Onodera, O. Shimomura, K. Takemura, H. Nakae, T. Matsuda and T. Hirai, Phys. Rev. B 45 (1992) p. 10226.

66. T. Yagi, W. Utsumi, M. Yamakata, T. Kikegawa and O. Shimomura, Phys. Rev. B 46 (1992) p. 6031.

67. V. L. Solozhenko and O. O. Kurakevych, Acta Crystallogr. Sect. B 61 (2005) p. 498.

68. V. L. Solozhenko, O. O. Kurakevych and A. Y. Kuznetsov, J. Appl. Phys. 102 (2007) p. 063509.

69. V. L. Solozhenko, O. O. Kurakevych, E. G. Solozhenko, J. Chen and J. B. Parise, Solid State Comm. 137 (2006) p. 268.

70. A. V. Talyzin, V. L. Solozhenko, O. O. Kurakevych, T. Szabó, I. Dékány, A. Kurnosov and V. Dmitriev, Angewandte Chemie Int. Ed. 47 (2008) p. 8268. 
Table 1.

Theoretical values of Vickers hardness for some hypothetical superhard high-pressure phases

\begin{tabular}{|c|c|c|c|c|c|c|c|c|c|}
\hline Solids ${ }^{\mathrm{a}}$ & $\begin{array}{c}-\Delta G_{f}^{\circ} \\
\mathrm{kJ} \mathrm{mole}^{-1}\end{array}$ & $\begin{array}{c}-\Delta G_{a t}^{\circ} \\
\mathrm{kJ} \mathrm{mole}^{-1}\end{array}$ & $\begin{array}{c}V \\
\mathrm{~cm}^{3} \mathrm{~mole}^{-1}\end{array}$ & $N$ & $\begin{array}{c}\frac{2 \Delta G_{a t}^{\circ}}{N V} \\
\mathrm{GPa} \\
\end{array}$ & $\chi_{X}$ & $\chi_{Y}$ & $\beta$ & $\begin{array}{c}H_{V \text { theor }}, \\
\text { GPa }\end{array}$ \\
\hline $\mathrm{C}_{3} \mathrm{~N}_{4}$ & $60^{\mathrm{b}}$ & 3896.0 & $35.45^{\mathrm{b}}$ & 4 & 55.0 & 3.04 & 2.55 & 0.8393 & 41.7 \\
\hline $\mathrm{c}-\mathrm{BC}_{5}$ & $96^{\mathrm{b}}$ & 3971.1 & 21.32 & 4 & 93.1 & 2.55 & 2.04 & 0.7903 & 70.6 \\
\hline $\mathrm{c}-\mathrm{BC}_{3}$ & $62^{b}$ & 2594.6 & $14.09^{b}$ & 4 & 92.1 & 2.55 & 2.04 & 0.7903 & 73.2 \\
\hline$d-B^{c}$ & $0^{\mathrm{b}}$ & 518.8 & $4.242^{c}$ & 4 & 61.2 & 2.04 & 2.04 & 1 & 61.2 \\
\hline $\mathrm{hp}-\mathrm{B}_{2} \mathrm{O}_{3}$ & $1272.9^{b}$ & 3005.7 & $22.29^{\mathrm{d}}$ & 4 & 67.4 & 3.44 & 2.04 & 0.5543 & 37.4 \\
\hline hp- $\mathrm{B}_{2} \mathrm{O}_{3}$ & $1272.9^{b}$ & 3005.7 & $21.0^{\mathrm{e}}$ & 6 & 47.07 & 3.44 & 2.04 & 0.5543 & 26.4 \\
\hline $\begin{array}{c}\mathrm{CO}_{2} \\
\left(\alpha-\mathrm{SiO}_{2}\right)\end{array}$ & $294.0^{\mathrm{b}}$ & 1429.0 & $14.5^{b}$ & 4 & 49.3 & 3.44 & 2.55 & 0.725 & 35.7 \\
\hline$" \mathrm{~d}-\mathrm{C}_{2} \mathrm{O}$ "f & $148.7^{b}$ & 1722.9 & 10.64 & 4 & 81.0 & 3.44 & 2.55 & 0.725 & 58.7 \\
\hline $\mathrm{d}-\mathrm{CO}$ & $37.0^{\mathrm{b}}$ & 940.0 & 5.90 & 4 & 79.7 & 3.44 & 2.55 & 0.725 & 57.8 \\
\hline
\end{tabular}

a the calculations have been performed with $\varepsilon=1$; thermodynamic data from Refs. $18,20,22-26$

b the values have been estimated using the standard Gibbs energies of formation of known compounds in the corresponding binary systems;

c the length of B-B bond taken as $1.66 \AA$;

d molar volume of $\beta-\mathrm{B}_{2} \mathrm{O}_{3}$ phase;

e estimation for the lowest possible limit of the molar volume of $\mathrm{B}_{2} \mathrm{O}_{3}$ according to the covalent radius data [18];

f buckled layers of graphite are connected by oxygen atoms. 

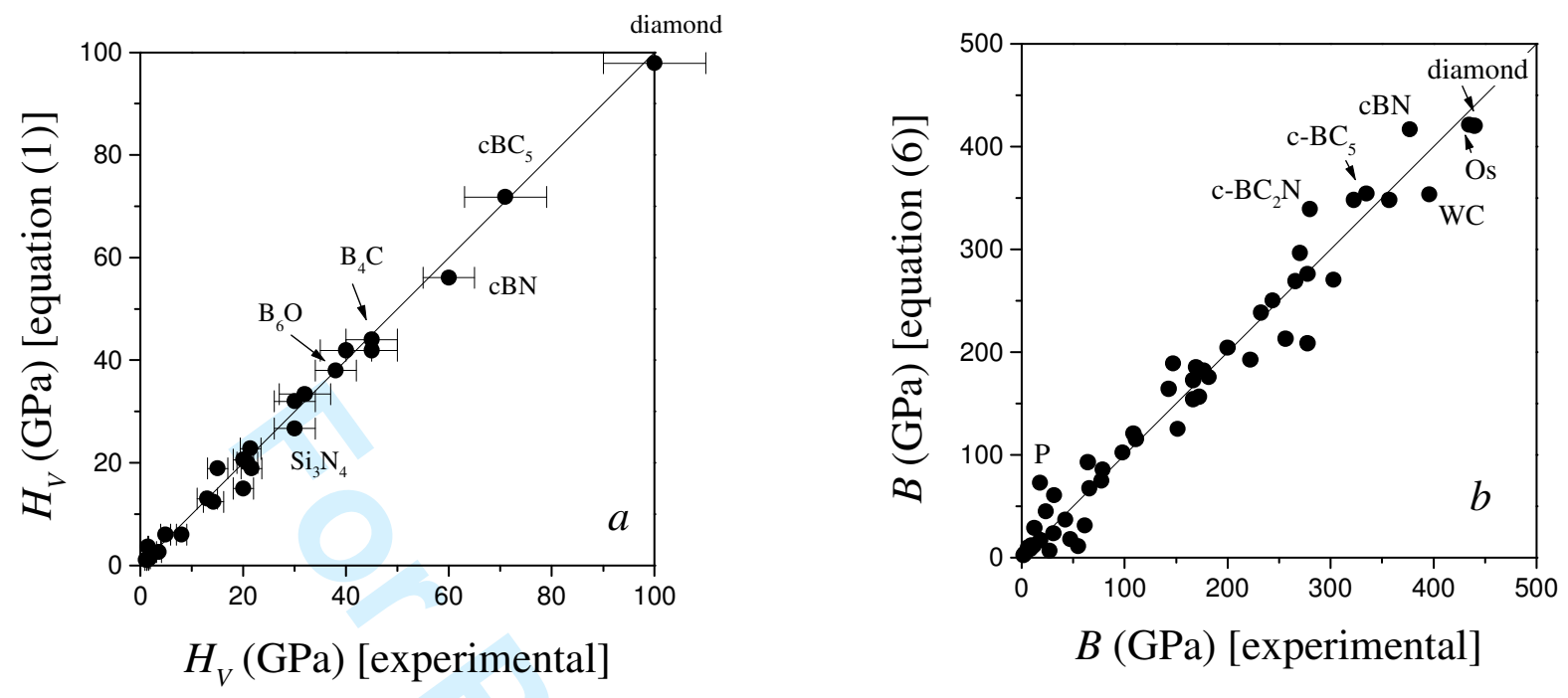

Fig. 1 Hardness and bulk modulus as a function of Gibbs energy of atomization. (a) Comparison of experimental values of Vickers hardness of various phases with corresponding values calculated in the framework of the model proposed in the present paper [equation (1)]. (b) Comparison of experimental bulk moduli of various phases with values calculated by equation (6). 
Fig. 2 Hardness as a function of enthalpy at a melting point. Comparison of experimental values of Vickers hardness of various phases with corresponding values calculated using equation (4). 

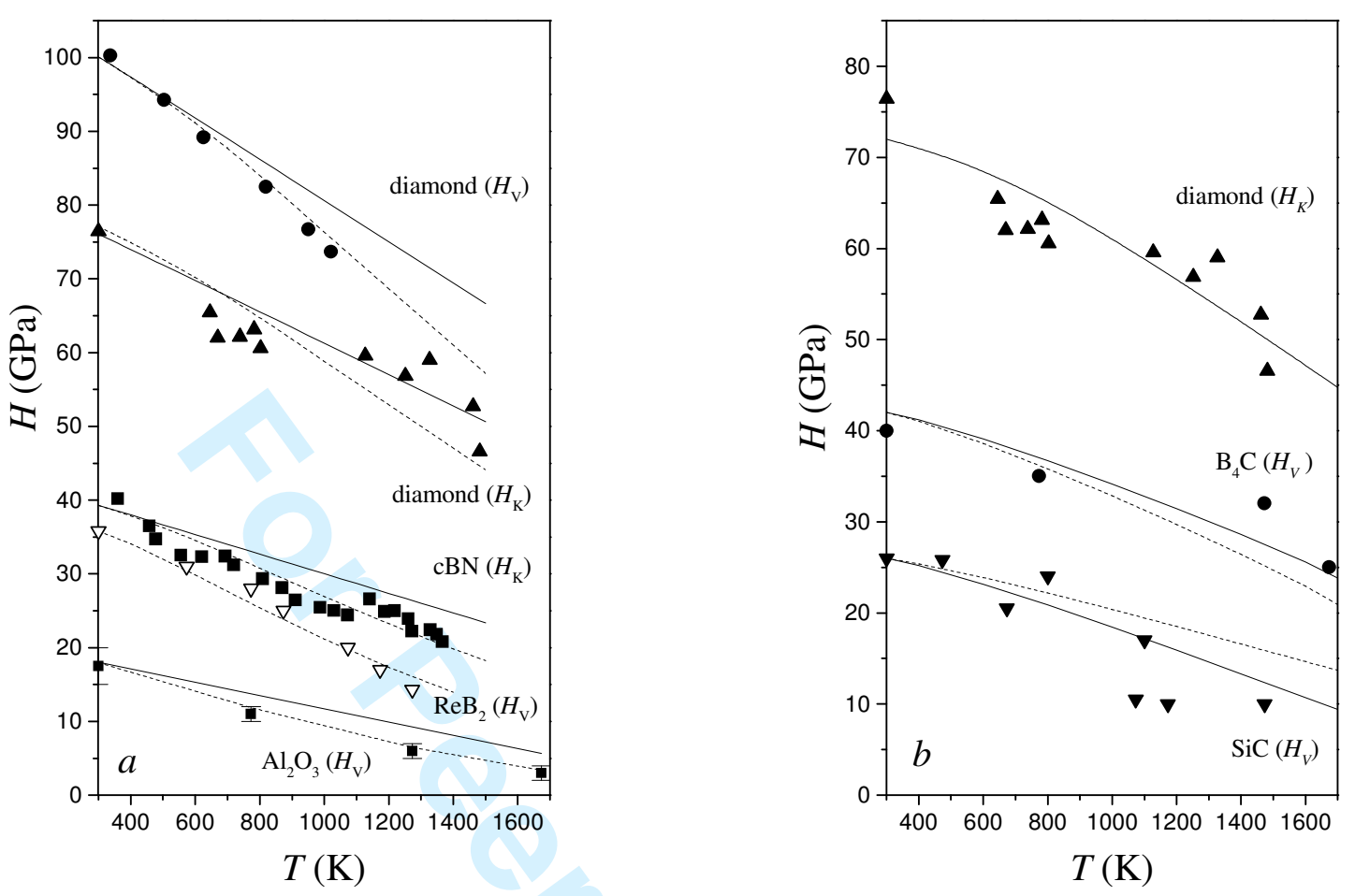

Fig. 3 Temperature dependence of hardness of single-crystal diamond, polycrystalline cBN (mean particle size of $5 \mu \mathrm{m}$ ), single-crystal $\mathrm{ReB}_{2}$, and $\mathrm{B}_{4} \mathrm{C}$-, $\mathrm{SiC}$ - and $\mathrm{Al}_{2} \mathrm{O}_{3}$-based ceramics. The symbols represent the experimental data obtained by static indentation $[4,20,54,55,59,60]$. (a) The lines show the results of calculation using equation (8) under assumption that $\alpha=$ const (solid line) and using equation (9) for $\alpha$ (dashed line). (b) The lines correspond to the calculations using equations (10) (dashed line) and (11) (solid line). 


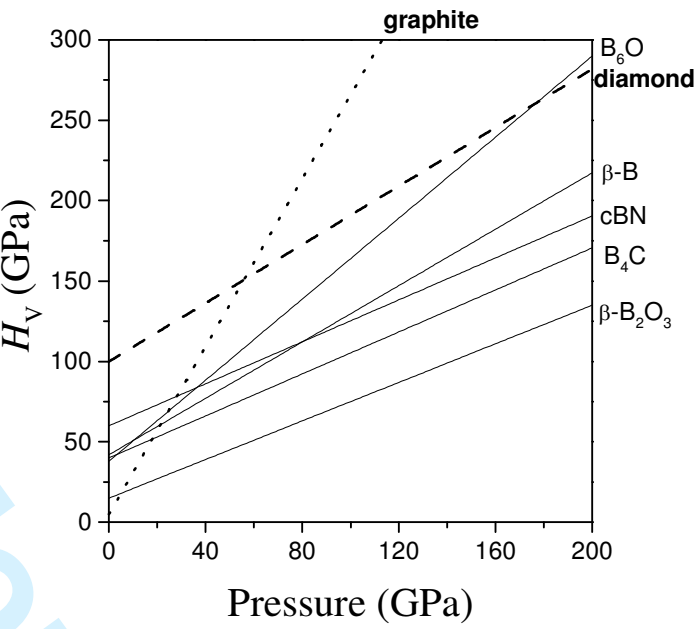

Fig. 4 Prediction of pressure dependence of hardness using experimental data on bulk moduli and their pressure derivatives [equation (15)]. 